\title{
Diaminouronium Nitriminotetrazolates - Thermally Stable Explosives
}

\begin{tabular}{|c|c|}
\hline Journal: & Zeitschrift für Anorganische und Allgemeine Chemie \\
\hline Manuscript ID: & zaac. $201000231 . \mathrm{R} 1$ \\
\hline Wiley - Manuscript type: & Article \\
\hline $\begin{array}{r}\text { Date Submitted by the } \\
\text { Author: }\end{array}$ & 23-Jun-2010 \\
\hline Complete List of Authors: & $\begin{array}{l}\text { Klapoetke, Thomas; LMU } \\
\text { Stierstorfer, Joerg; LMU, Cheistry } \\
\text { Fischer, Niko; LMU } \\
\text { Piercey, Davin; LMU, Cheistry } \\
\text { Scheutzow, Susanne; LMU, Cheistry }\end{array}$ \\
\hline Keywords: & Crystal Structure, Energetic Material, Sensitivities, Tetrazoles \\
\hline
\end{tabular}

\section{S ScholaroNE \\ Manuscript Central}




\title{
Diaminouronium Nitriminotetrazolates - Thermally Stable Explosives
}

\author{
Niko Fischer, ${ }^{[\mathrm{a}]}$ Thomas M. Klapötke, ${ }^{*[\mathrm{a}]}$ Davin Piercey, ${ }^{[\mathrm{a}]}$ Susanne Scheutzow \\ and Jörg Stierstorfer ${ }^{[a]}$
}

In memory of Herbert Schumann, an outstanding chemist and great friend

Keywords: Crystal Structure; Detonation Parameters; Energetic Materials; Sensitivities; Tetrazoles;



\begin{abstract}
:
Diaminouronium 5-nitriminotetrazolate (1) and diaminouronium 1-methyl-5-nitriminotetrazolate (2) were synthesized by the reaction of diaminourea with 5-nitriminotetrazole (3) and 1-methyl-5-nitriminotetrazole (4), respectively. The energetic compounds 1 and 2 were fully characterized by single crystal X-ray diffraction, NMR spectroscopy, IR- and Raman spectroscopy as well as DSC measurements. The sensitivities towards impact, friction and electrical discharge were determined. Several detonation parameters (e.g. heat of explosion, detonation velocity) were computed by the EXPLO5 computer code based on calculated (CBS-4M) heats of formation and X-ray densities. In addition, the detonation velocity of 1 was experimentally determined and compared to the computed values.
\end{abstract}

Keywords: Crystal Structure, Energetic Materials, Sensitivities, Tetrazoles.

\section{Introduction}

Nitrogen rich materials play an important role in the design of new energetic materials for use in propellants, explosives, and pyrotechnics [1]. For a nitrogen rich material to find practical application as a high explosive it needs to posses high thermal and mechanical stabilities, while at the same time satisfying the increasing demand for higher performing (high detonation velocity, pressure and heat of explosion) materials. Unfortunately, in many cases high performance and low sensitivity appear to be mutually exclusive; many high performing materials are not stable enough to find practical use [2] and many materials with the desired sensitivity do not posses the performance requirements of a material to replace a commonlyused explosive [3]. This trend is exemplified in the range of 5-membered azoles from pyrazole to pentazole, where pyrazole is not used in energetics due to low performance, and 
the few pentazole derivatives known are highly unstable [4]. One of the most promising heterocyclic backbones for the preparation of high-performing energetics is the tetrazole ring. Possessing high heats of formation resulting from the nitrogen-nitrogen bonds, ring strain, and high density, the tetrazole ring has allowed the preparation of high performing primary [5] and secondary [6] explosives, illustrating the dynamic nature of the tetrazole ring; depending on the ring substitutents and anion/cation pairing, tetrazole based energetics can span the spectrum of sensitivity from insensitive to highly sensitive (primary explosives). Additionally, due to their aromatic ring, tetrazoles are generally thermally stable. Of the tetrazoles suitable for use in secondary explosives, nitriminotetrazoles are one of the most promising due to high thermal stability [7].

Apart from the high heats of formation, for a molecule or salt to be a high-performing energetic, a high oxygen balance is required. The oxygen balance is given in percent and represents the amount of oxygen with respect to the molar mass of the molecule, which is necessary to convert all of its non-oxidizing content to their respective oxides and is easily calculated by the equation $\Omega(\%)=(w \mathrm{O}-2 x \mathrm{C}-1 / 2 y \mathrm{H}-2 z \mathrm{~S}) \cdot 1600 / \mathrm{M}(w$ : number of oxygen atoms, $x$ : number of carbon atoms, $y$ : number of hydrogen atoms, $z$ : number of sulfur atoms). Previous work with nitriminotetrazoles and especially alkylated nitriminotetrazoles [7], has led to compounds with high performance despite negative oxygen balances. The use of oxygen-containing cations with nitriminotetrazoles to improve the oxygen balance of the final nitriminotetrazolate salts is a previously unexplored field. In this work we describe the synthesis and properties of two new energetic nitriminotetrazoles containing the diaminouronium cation.

\section{Results and Discussion}

\section{Synthesis}

The synthetic routes to compounds $\mathbf{1}$ and $\mathbf{2}$ are depicted in Scheme 1. As they are both ionic species, they are accessible by facile Brønstead acid base chemistry. An aqueous solution of diaminourea, which is readily soluble in water, is reacted with an equimolar amount of 5nitriminotetrazole and 1-methyl-5-nitriminotetrazole respectively, which also were dissolved in warm water prior to addition.<smiles>NNC(=O)NNC(=O)NNNC(=O)NN[NH3+]</smiles>

Scheme 1. Synthesis of $\mathbf{1}$ and $\mathbf{2}$ via Brønstead acid base chemistry 


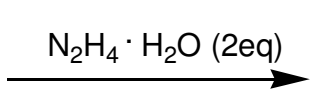<smiles>NNC(=O)NN</smiles><smiles>Nc1nnn[nH]1</smiles><smiles>CC(C)[R6](=O)(=O)O[Na]</smiles><smiles>O=[N+]([O-])N=c1[nH]nn[nH]1</smiles><smiles>Nc1nnn[nH]1</smiles><smiles>Cn1nn[nH]/c1=N\[O+]([O-])[O-]</smiles>

Scheme 2. Synthesis of the starting materials.

\section{Crystal Structures}

The single crystal X-ray diffraction data was collected using an Oxford Xcalibur3 diffractometer with a Spellman generator (voltage $50 \mathrm{kV}$, current $40 \mathrm{~mA}$ ) and a KappaCCD detector. The data collection was undertaken using the CRYSALIS CCD software [10] and the data reduction was performed with the CRYSALIS RED software [10]. The structure was solved with SIR-92 [11] and refined with SHELXL-97 [12] implemented in the program package WinGX [13] and finally checked using PLATON [14]. Due to the chiral space groups in both structure, the Friedel pairs were merged. In all structures potential hydrogen atoms have been observed and freely refined. Selected data and parameters from the X-ray data collection and refinement are given in Table 1. Further information regarding the crystalstructure determination have been deposited with the Cambridge Crystallographic Data Centre [15] as supplementary publication Nos XXX (1) and XXX (2).

Table 1. X-ray data and parameters

\begin{tabular}{lll}
\hline & $\mathbf{1}$ & $\mathbf{2}$ \\
\hline Formula & $\mathrm{C}_{2} \mathrm{H}_{8} \mathrm{~N}_{10} \mathrm{O}_{3}$ & $\mathrm{C}_{3} \mathrm{H}_{10} \mathrm{~N}_{10} \mathrm{O}_{3}$ \\
Form. weight $\left[\mathrm{g} \mathrm{mol}^{-1}\right]$ & 220.18 & 234.12 \\
Crystal system & Monoclinic & Orthorhombic \\
Space group & $P n$ (No. 7) & $P 2_{1} 2_{1} 2_{1}$ (No. 19) \\
Color / Habit & Colorless rods & Colorless plates
\end{tabular}




\begin{tabular}{|c|c|c|}
\hline Size, mm & $0.08 \times 0.26 \times 0.28$ & $0.06 \times 0.18 \times 0.20$ \\
\hline$a[\AA]$ & $3.7569(2)$ & $4.9434(2)$ \\
\hline$b[\AA]$ & $12.3854(6)$ & $13.6462(6)$ \\
\hline$c[\AA]$ & $8.7087(5)$ & $14.5469(6)$ \\
\hline$\alpha\left[^{\circ}\right]$ & 90 & 90 \\
\hline$\beta\left[^{\circ}\right]$ & $92.106(5)$ & 90 \\
\hline$\gamma\left[{ }^{\circ}\right]$ & 90 & 90 \\
\hline$V\left[\AA^{3}\right]$ & $404.95(4)$ & $981.21(7)$ \\
\hline$Z$ & 2 & 4 \\
\hline$\rho_{\text {calc. }}\left[\mathrm{g} \mathrm{cm}^{-3}\right]$ & 1.806 & 1.585 \\
\hline$\mu\left[\mathrm{mm}^{-1}\right]$ & 0.159 & 0.136 \\
\hline$F(000)$ & 228 & 488 \\
\hline$\lambda_{\mathrm{MoK \alpha}}[\AA]$ & 0.71073 & 0.71073 \\
\hline$T[\mathrm{~K}]$ & 173 & 173 \\
\hline Theta Min-Max [ $\left.{ }^{\circ}\right]$ & $4.7,26.0$ & $4.3,25.5$ \\
\hline Dataset & $-5: 4 ;-18: 15 ;-9: 13$ & $-6: 5 ;-18: 16 ;-19: 18$ \\
\hline Reflections collected & 2072 & 5910 \\
\hline Independent reflections & 1095 & 1807 \\
\hline$R_{\text {int }}$ & 0.0244 & 0.0374 \\
\hline Observed reflections & 995 & 1354 \\
\hline No. parameters & 168 & 185 \\
\hline$R_{1}$ (obs) & 0.0265 & 0.0311 \\
\hline $\mathrm{w} R_{2}$ (all data) & 0.0548 & 0.0526 \\
\hline$S$ & 0.965 & 0.840 \\
\hline Resd. dens. $\left[\mathrm{e} \AA^{-3}\right]$ & $-0.18,0.15$ & $-0.19,0.15$ \\
\hline Device type & Oxford Xcalibur3 CCD & Oxford Xcalibur3 CCD \\
\hline Solution & SIR-92 & SIR-92 \\
\hline Refinement & SHELXL-97 & SHELXL-97 \\
\hline Absorption correction & multi-scan & multi-scan \\
\hline $\mathrm{CCDC}$ & --- & --- \\
\hline
\end{tabular}

Diaminouronium 5-nitriminotetrazolate (1) crystallizes in the monoclinic chiral space group $P n$. Its density of $1.806 \mathrm{~g} \mathrm{~cm}^{-3}$ is quite high in comparison with other tetrazolate salts [16]. The molecular unit is shown in Figure 1. The structure of the 5-nitriminotetrazolate anion is comparable to that found in corresponding copper(II) salts [17]. Bond lengths are given in Table 2. The diaminouronium cation follows the structure described e.g. for diaminouronium 5-(4-amino-1,2,5-oxadiazol-3-yl)tetrazolate [18]. 

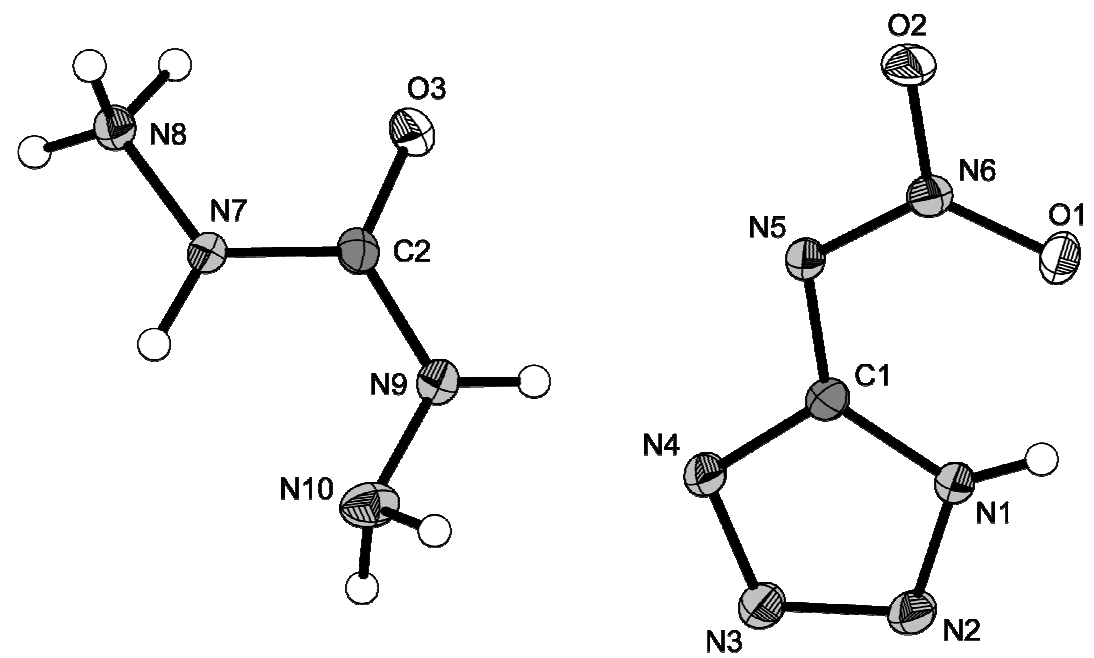

Figure 1. Molecular unit of diamouronium 5-nitriminotetrazolate (1). Ellipsoids of nonhydrogen atoms are drawn at the $50 \%$ probability level.

The packing is strongly influenced by an intense hydrogen-bond network. The formation of all intramolecular (graph sets [19] DAU $\mathbf{U}^{+}: 2 \times \mathrm{S}\left(1,1(5)\right.$; graph set $\mathbf{H A t N O}_{2}^{-}: \mathrm{S}(1,1(6))$ as well as of selected intermolecular H-bonds is shown in Figure 2.

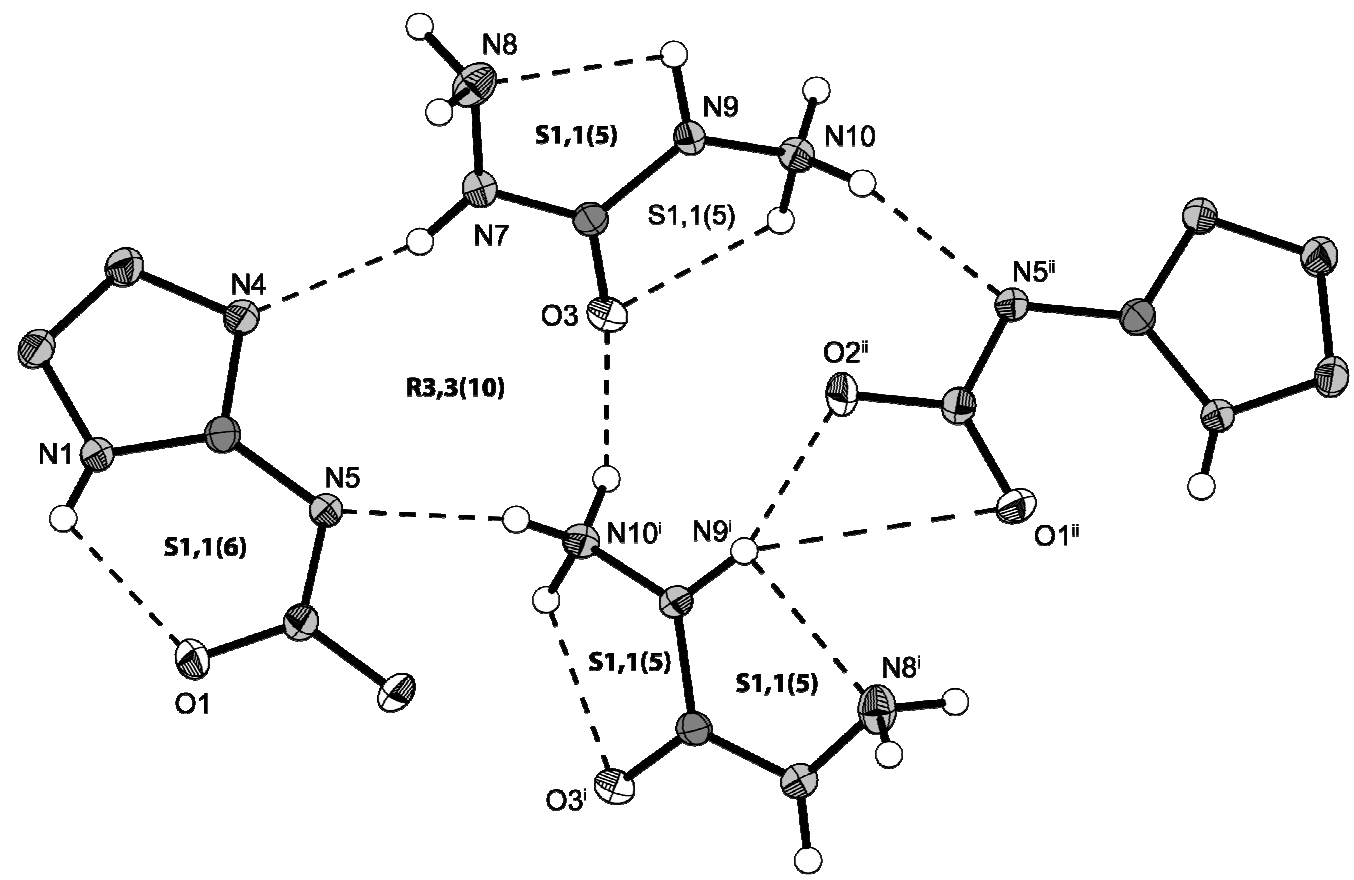

Figure 2. View on selected hydrogen bonds in the structure of $\mathbf{1}$. Symmetry codes (i) $-0.5+x$, $1-\mathrm{y}, 0.5+\mathrm{z}$; (ii) $0.5+\mathrm{x}, 1-\mathrm{y},-0.5+\mathrm{z}$

Diaminouronium 1-methyl-5-nitriminotetrazolate (2) crystallizes in the orthorhombic chiral space group $P 2{ }_{1} 2{ }_{1} 2{ }_{1}$. Its density of $1.585 \mathrm{~g} \mathrm{~cm}^{-3}$ is significantly lower than that of $\mathbf{1}$, however, it is in the range of other 1-methyl-5-nitriminotetrazolate salts with nitrogen-rich counter cations [7]. The anions are planar $\left(<\left(\mathrm{O} 1-\mathrm{N} 6-\mathrm{C} 1-\mathrm{N} 4=1.22(2)^{\circ}\right)\right.$ and show comparable bond lengths and angles to copper(II) 1-methyl-5-nitriminotetrazolates in the literature [20]. 



Figure 3. Molecular unit of diamouronium 1-methyl-5-nitriminotetrazolate (2). Ellipsoids of non-hydrogen atoms are drawn at the $50 \%$ probability level.

The structure of $\mathbf{2}$ also shows an intense hydrogen-bond network. All of the hydrogen atoms of the diaminouronium cations are involved in hydrogen bridges, which are shown in Figure 4.

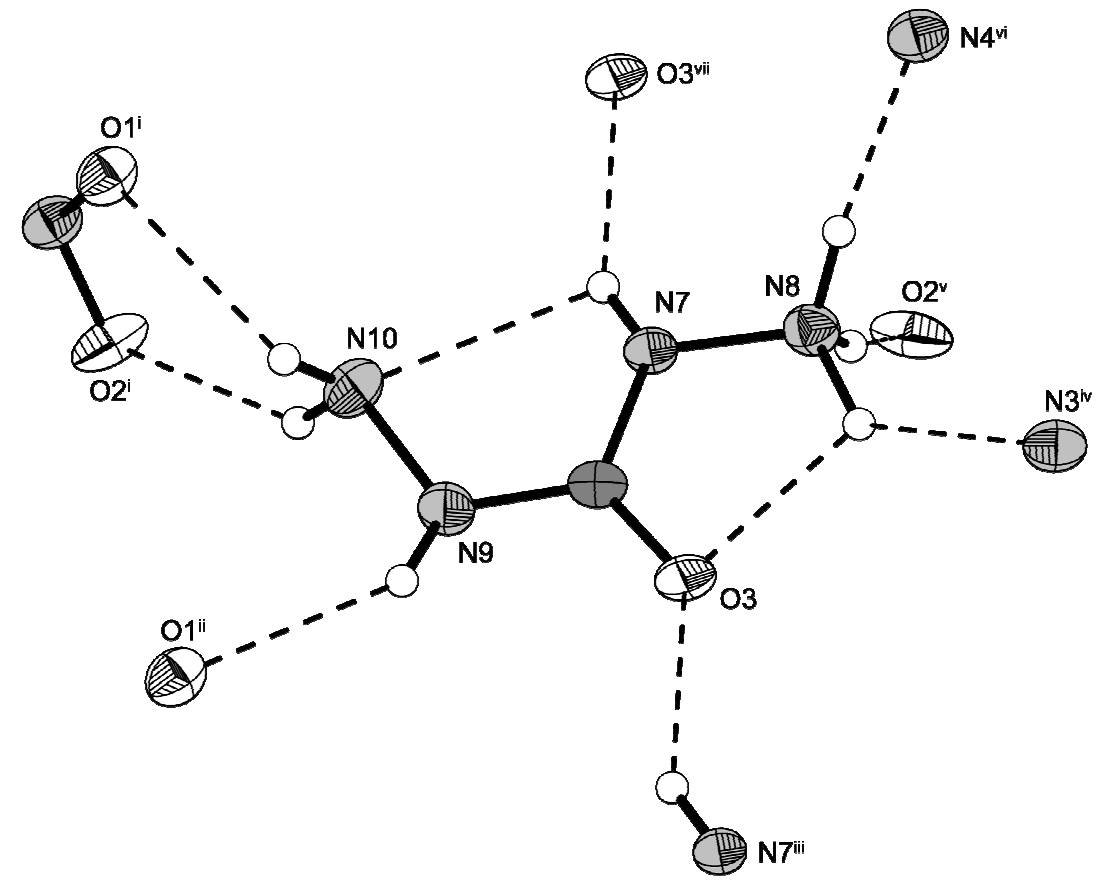

Figure 4. View on the hydrogen bridges of one diaminouronium cation in the structure of 2. Symmetry codes (i) 2-x, 0.5+y, 0.5-z; (ii) 1-x, 0.5+y, 0.5-z; (iii) -1+x, y, z; (iv) 0.5-x, -y, $0.5+z$; (v) $-1+x, y, z$; (vi) $1.5-x,-y, 0.5+z$ (vii) $1+x, y, z$ 
Table 2. Bond lengths and bond angles of $\mathbf{1}$ and $\mathbf{2}$.

\begin{tabular}{lll}
\hline atoms & $\mathbf{1}$ & $\mathbf{2}$ \\
\hline O1-N6 & $1.240(2)$ & $1.249(2)$ \\
O2-N6 & $1.269(2)$ & $1.276(2)$ \\
N5-N6 & $1.313(2)$ & $1.315(2)$ \\
N5-C1 & $1.377(3)$ & $1.372(3)$ \\
N1-C1 & $1.338(3)$ & $1.346(3)$ \\
N4-C1 & $1.330(3)$ & $1.341(3)$ \\
N1-N2 & $1.347(3)$ & $1.347(2)$ \\
N2-N3 & $1.298(2)$ & $1.297(3)$ \\
N3-N4 & $1.355(3)$ & $1.370(2)$ \\
N1-C2 & & $1.459(3)$ \\
O3-C2(3) & $1.235(3)$ \\
N7-N8 & $1.244(2)$ & $1.407(3)$ \\
N7-C2(3) & $1.419(2)$ & $1.346(3)$ \\
N9-N10 & $1.386(2)$ & $1.422(3)$ \\
N9-C2(3) & $1.417(3)$ & $1.338(3)$ \\
\hline
\end{tabular}

\section{Spectroscopy}

Both compounds described were investigated using ${ }^{1} \mathrm{H}$ and ${ }^{13} \mathrm{C}$ NMR spectroscopy. For better comparison with literature values, all spectra were measured using $d_{6}$-DMSO as solvent and all chemical shifts are given with respect to TMS $\left({ }^{1} \mathrm{H},{ }^{13} \mathrm{C}\right)$.

To identify the specified compounds NMR spectroscopy, especially carbon NMR spectra are a valuable method since the spectra are dominated by only two or three signals respectively. The signals for the ring carbon atoms in $\mathbf{1}$ and $\mathbf{2}$ can be found at $158.0 \mathrm{ppm}$ (1) and $157.6 \mathrm{ppm}$ (2). Hence, no shift of this signal in the anionic species is observed due to the methylation of the tetrazole ring. The signal of the carbon atom of the carbonyl moiety of the cation is observed at around $159.5 \mathrm{ppm}$. An additional methyl signal at $33.0 \mathrm{ppm}$ for the methylated nitriminotetrazolate can be assigned and its position is in accordance with values found in literature [7].

IR and Raman spectroscopy is also suitable for the identification of the described nitriminotetrazolate salts. IR and Raman spectra of both compounds were measured and the absorptions were assigned according to commonly observed values found in literature [7, 2123]. The range between 3550 and $3230 \mathrm{~cm}^{-1}$ is mainly determined by the $\mathrm{N}-\mathrm{H}$ stretching vibrations of the diaminouronium cation. For the methylated compound 2 the symmetric $\mathrm{C}-\mathrm{H}$ stretching vibration of the methyl group can nicely be observed in the Raman spectrum at $2957 \mathrm{~cm}^{-1}$. Another characteristic IR absorption is the $\mathrm{C}=\mathrm{O}$-stretching vibration of the cation at $1692 \mathrm{~cm}^{-1}$ in both cases. The tetrazole ring system itself exhibits stretching and deformation 
vibrations that can be detected as a set of signals lying in the range from $1031 \mathrm{~cm}^{-1}$ to $1637 \mathrm{~cm}^{-1}$ with a $\mathrm{C}=\mathrm{N}$-stretching vibration between 1617 and $1637 \mathrm{~cm}^{-1}$.

\section{Sensitivities and thermal behavior}

The impact sensitivity tests were carried out according to STANAG 4489 [24] modified instruction [25] using a BAM (Bundesanstalt für Materialforschung) drophammer [26]. The friction sensitivity tests were carried out according to STANAG 4487 [27] modified instruction [28] using the BAM friction tester. The classification of the tested compounds results from the "UN Recommendations on the Transport of Dangerous Goods" [29]. All compounds were tested upon the sensitivity towards electrical discharge using the Electric Spark Tester ESD 2010 EN [30]. The values for the impact sensitivities could be determined to $5 \mathrm{~J}$ (2) and $3 \mathrm{~J}$ (3) and therefore both compounds have to be classified as sensitive and very sensitive towards impact. The same classification applies to the friction sensitivity. With values of $108 \mathrm{~N}$ (1) and $160 \mathrm{~N}$ (2) both nitriminotetrazolate salts are sensitive towards friction. Compared to the triaminoguanidinium salt of 1-methyl-5-nitriminotetrazole, which was formerly investigated by our research group [7] and exhibits values of $6 \mathrm{~J}$ and $240 \mathrm{~N}$, the diaminouronium salt is more sensitive especially towards friction. The sensitivities towards electrical discharge were determined to be $0.20 \mathrm{~J}(2)$ and $0.15 \mathrm{~J}(3)$.

Differential scanning calorimetry (DSC) measurements to determine the melt- and decomposition temperatures of $\mathbf{1}$ and $\mathbf{2}$ (about $1.5 \mathrm{mg}$ of each energetic material) were performed in covered Al-containers with a hole $(0.1 \mathrm{~mm})$ in the lid for gas release and a nitrogen flow of $20 \mathrm{~mL}$ per minute on a Linseis PT 10 DSC [31] calibrated by standard pure indium and zinc at a heating rate of $5^{\circ} \mathrm{C} \mathrm{min}^{-1}$. The decomposition temperatures are given as absolute onset temperatures and both compounds decompose at around $200^{\circ} \mathrm{C}$ with a slightly higher value for methylated $2\left(204^{\circ} \mathrm{C}\right)$ compared to $198^{\circ} \mathrm{C}$ for unmethylated $\mathbf{1}$. Compared to triaminoguanidinium $\left(210^{\circ} \mathrm{C}\right)$ and diaminoguanidinium 1-methyl-5-nitriminotetrazolate $\left(208^{\circ} \mathrm{C}\right)$, where the oxo $(=\mathrm{O})$ moiety of the cation is exchanged by a hydrazo $\left(=\mathrm{NH}-\mathrm{NH}_{2}\right)$ and an imino $(=\mathrm{NH})$ moiety respectively, there is not a siginficant difference in thermal stability.

\section{Theoretical Calculations}

All calculations were carried out using the Gaussian G03W (revision B.03) program package [32]. The enthalpies $(\mathrm{H})$ and free energies $(\mathrm{G})$ were calculated using the complete basis set (CBS) method of Petersson and coworkers in order to obtain very accurate energies. The CBS models use the known asymptotic convergence of pair natural orbital expressions to extrapolate from calculations using a finite basis set to the estimated complete basis set limit. CBS-4 begins with a HF/3-21G(d) geometry optimization; the zero point energy is computed at the same level. It then uses a large basis set SCF calculation as a base energy, and a MP2/6$31+\mathrm{G}$ calculation with a CBS extrapolation to correct the energy through second order. A MP4(SDQ)/6-31+(d,p) calculation is used to approximate higher order contributions. In this study we applied the modified CBS-4M method ( $\mathrm{M}$ referring to the use of minimal population localization) which is a re-parametrized version of the original CBS-4 method and also includes some additional empirical corrections [33]. The enthalpies of the gas-phase species $\mathrm{M}$ were computed according to the atomization energy method (eq. 1) (Tables 3-5) [34].

$$
\Delta_{\mathrm{f}} H_{(\mathrm{g}, \mathrm{M}, 298)}^{\circ}=H_{(\text {Molecule, 298) }}-\sum H^{\circ}\left(\text { Atoms, 298) }+\sum \Delta_{\mathrm{f}} H_{(\text {Atoms, } 298)}^{\circ}\right.
$$


Table 3.

\section{CBS-4M results}

\begin{tabular}{llll}
\hline & point group & $-H^{298} /$ a.u. & NIMAG \\
\hline DAU $^{+}$ & $C_{s}$ & 335.795706 & 0 \\
HAtNO $_{2}{ }^{-}$ & $C_{s}$ & 516.973495 & 0 \\
1MeAtNO $_{2}{ }^{-}$ & $C_{1}$ & 556.194636 & 0 \\
$\mathrm{H}$ & & 0.500991 & 0 \\
$\mathrm{C}$ & & 37.786156 & 0 \\
$\mathrm{~N}$ & & 54.522462 & 0 \\
$\mathrm{O}$ & & 74.991202 & 0 \\
\hline
\end{tabular}

Table 4. Literature values for atomic $\Delta H_{\mathrm{f}}^{\circ 298} / \mathrm{kcal} \mathrm{mol}^{-1}$

\begin{tabular}{ll}
\hline & NIST [35] \\
\hline $\mathrm{H}$ & 52.1 \\
$\mathrm{C}$ & 171.3 \\
$\mathrm{~N}$ & 113.0 \\
$\mathrm{O}$ & 59.6 \\
\hline
\end{tabular}

Table 5.

Enthalpies of the gas-phase species $\mathrm{M}$.

\begin{tabular}{lll}
\hline $\mathbf{M}$ & Formula & $\Delta_{\mathrm{f}} H^{\circ}(\mathrm{g}, \mathrm{M}) / \mathrm{kcal} \mathrm{mol}^{-1}$ \\
\hline DAU $^{+}$ & $\mathrm{CH}_{7} \mathrm{~N}_{4} \mathrm{O}$ & 155.6 \\
HAtNO $_{2}^{-}$ & $\mathrm{CHN}_{6} \mathrm{O}_{2}$ & 35.9 \\
1MeAtNO $_{2}^{-}$ & $\mathrm{C}_{2} \mathrm{H}_{3} \mathrm{~N}_{6} \mathrm{O}_{2}$ & 166.3
\end{tabular}

The solid state energy of formations (Table 8$)$ of $\mathbf{1}$ and $\mathbf{2}$, the lattice energy $\left(U_{\mathrm{L}}\right)$ and lattice enthalpy $\left(\Delta H_{\mathrm{L}}\right)$ (Table 7) were calculated from the corresponding molecular volumes (Table 6) according to the equations provided by Jenkins [36]. With the calculated lattice enthalpy (Table 7) the gas-phase enthalpy of formation (Table 5) was converted into the solid state (standard conditions) enthalpy of formation (Table 8). These molar standard enthalpies of formation $\left(\Delta H_{\mathrm{m}}\right)$ were used to calculate the molar solid state energies of formation $\left(\Delta U_{\mathrm{m}}\right)$ according to equation (2) (Table 8).

$$
\Delta U_{\mathrm{m}}=\Delta H_{\mathrm{m}}-\Delta n R T(2)
$$

( $\Delta n$ being the change of moles of gaseous components)

Table 6. Molecular volumes.

\begin{tabular}{lll}
\hline & $\mathrm{V}_{\mathrm{M}} / \AA^{3}$ & $\mathrm{~V}_{\mathrm{M}} / \mathrm{nm}^{3}$ \\
\hline DAU $^{+}$ & 81 & 0.081 \\
HAtNO $_{2}^{-}$ & 121 & 0.121 \\
1MeAtNO $_{2}^{-}$ & 164 & 0.164 \\
\hline
\end{tabular}

Table 7. Lattice energies and lattice enthalpies.

\begin{tabular}{cccc}
\hline $\mathrm{V}_{\mathrm{M}} / \mathrm{nm}^{3}$ & $U_{\mathrm{L}} / \mathrm{kJ} \mathrm{mol}^{-1}$ & $\Delta H_{\mathrm{L}} / \mathrm{kJ} \mathrm{mol}^{-1}$ & $\Delta H_{\mathrm{L}} / \mathrm{kcal} \mathrm{mol}^{-1}$ \\
\hline
\end{tabular}




\begin{tabular}{lllll}
\hline $\mathbf{1}$ & 0.202 & 503.6 & 507.1 & 121.1 \\
$\mathbf{2}$ & 0.245 & 478.7 & 482.2 & 115.2 \\
\hline
\end{tabular}

Table 8. Solid state enthalpies and energies of formation $\left(\Delta_{\mathrm{f}} U^{\circ}\right)$

\begin{tabular}{lllllll}
\hline & $\begin{array}{l}\Delta_{\mathrm{f}} H^{\circ}(\mathrm{s}) / \\
\mathrm{kcal} \mathrm{mol}\end{array}$ & $\begin{array}{l}\Delta_{\mathrm{f}} H^{\circ}(\mathrm{s}) / \\
\mathrm{kJ} \mathrm{mol}^{-1}\end{array}$ & $\Delta \mathrm{n}$ & $\begin{array}{l}\Delta_{\mathrm{f}} U^{\circ}(\mathrm{s}) / \\
\mathrm{kJ} \mathrm{mol}^{-1}\end{array}$ & $\begin{array}{l}\mathrm{M} / \\
\mathrm{g} \mathrm{mol}^{-1}\end{array}$ & $\begin{array}{l}\Delta_{\mathrm{f}} U^{\circ}(\mathrm{s}) / \\
\mathrm{kJ} \mathrm{kg}^{-1}\end{array}$ \\
\hline $\mathbf{1}$ & 70.4 & 294.6 & 10.5 & 320.7 & 220.20 & 1456.3 \\
$\mathbf{2}$ & 80.1 & 335.4 & 11.5 & 363.9 & 234.23 & 1553.7 \\
\hline
\end{tabular}

\section{Detonation parameters}

The calculation of the detonation parameters was performed with the program package EXPLO5 (version 5.04) [37]. The program is based on the chemical equilibrium, steady-state model of detonation. It uses the Becker-Kistiakowsky-Wilson's equation of state (BKW EOS) for gaseous detonation products and Cowan-Fickett's equation of state for solid carbon. The calculation of the equilibrium composition of the detonation products is done by applying modified White, Johnson and Dantzig's free energy minimization technique. The program is designed to enable the calculation of detonation parameters at the CJ point. The BKW equation in the following form was used with the BKWN set of parameters $(\alpha, \beta, \kappa, \theta)$ as stated below the equations and $X_{\mathrm{i}}$ being the mol fraction of $i$-th gaseous product, $k_{\mathrm{i}}$ is the molar covolume of the $i$-th gaseous product [38]:

$p V / \mathrm{R} T=1+x \mathrm{e}^{\beta x} \quad x=\left(\kappa \Sigma X_{\mathrm{i}} k_{\mathrm{i}}\right) /[V(T+\theta)]^{\alpha}$

$\alpha=0.5, \beta=0.176, \kappa=14.71, \theta=6620$.

The detonation parameters calculated with the EXPLO5 program (V5.04) of compounds 1 and 2 using the experimentally determined densities (X-ray) are summarized in Table 9 and compared to the values calculated for the triaminoguanidinium 1-methyl-5nitriminotetrazolate and commonly used RDX.

Table 9. Detonation parameters

\begin{tabular}{|c|c|c|c|c|}
\hline & 1 & 2 & $\begin{array}{l}\text { TAG-1- } \\
\text { MeATNO }\end{array}$ & RDX \\
\hline$\rho / \mathrm{g} \mathrm{cm}^{-3}[\mathrm{a}]$ & 1.81 & 1.59 & 1.57 & 1.80 \\
\hline$\Omega / \%^{[\mathrm{b}]}$ & -36.3 & -54.7 & -64.5 & -21.6 \\
\hline$\Delta_{\mathrm{Ex}} U^{\circ} / \mathrm{kJ} \mathrm{kg}^{-1[\mathrm{c}]}$ & -4848 & -4850 & -4781 & -6125 \\
\hline$T_{d e t} / \mathrm{K}^{[\mathrm{d}]}$ & 3335 & 3246 & 3091 & 4236 \\
\hline$P_{C J} / \mathrm{kbar}^{[\mathrm{e}]}$ & 337 & 252 & 255 & 349 \\
\hline$V_{\text {Det. }} / \mathrm{m} \mathrm{s}^{-1[\mathrm{f}]}$ & 8979 & 8172 & 8309 & 8748 \\
\hline$V_{o} / \mathrm{L} \mathrm{kg}^{-1[\mathrm{~g}]}$ & 848 & 832 & 847 & 739 \\
\hline
\end{tabular}


Due to the much higher crystal density, the value for the detonation velocity for the parent compound 1 ( $\left.8979 \mathrm{~m} \mathrm{~s}^{-1}\right)$ exceeds the one of methylated $2\left(8127 \mathrm{~m} \mathrm{~s}^{-1}\right)$ by far and is even slightly higher when compared to RDX. The detonation pressures, however, only differ slightly. Again, a comparison of $\mathbf{2}$ to the triaminoguanidinium salt of 1-methyl-5nitriminotetrazole seems to be appropriate since both compounds only differ by one isolobal moiety which is the hydrazo $\left(=\mathrm{NH}-\mathrm{NH}_{2}\right)$ moiety in the case of the triaminoguanidinium salt and the oxo $(=\mathrm{O})$ moiety in 2 . There is only one value, which is in the same range for both compounds, which is the explosion energy (-4895 kJ kg-1 (2), -4888 kJ kg-1 (TAG-1$\left.\mathrm{MeATNO}_{2}\right)$ ). Not only the detonation velocity, but also the detonation pressure of the triaminoguanidinium salt is substantially higher than for the diaminouronium salt $\mathbf{2}$, even though having a slightly lower crystal density and a lower oxygen balance. In summary, the 5nitriminotetrazolate salt $\mathbf{1}$ shows much better performance than its methylated sister compound 2. Further, the exchange of the triaminoguanidinium cation by the diaminouronium cation does not improve the detonation performance in case of the 1-methyl-5nitriminotetrazolate anion, although one would expect a higher performance for oxygen containing cations such as the diaminouronium cation. The reason, why we observe inverse behaviour might be the connectivity of the oxygen in the cation. In the case of diaminourea, it is connected to a carbon atom, which therefore is already partially oxidized and does not release as much energy as a carbon atom with a lower oxidation state. Probably, oxygen containing cations involving a nitro functionality such as the aminonitroguanidinium cation lead to a better performance of the materials containing the respective anions investigated in this work.

\section{Velocity of detonation test}

In order to evaluate the detonation velocity of $\mathbf{1}$ experimentally, compound $\mathbf{1}$ was prepared on a $50 \mathrm{~g}$ scale. The detonation velocity tests were performed in an OZM laboratory detonation chamber (model KV-250). The measurement of the detonation velocity was performed using the OZM detonating velocity measuring system EXPLOMET-FO-2000. The use of the fiber optic technique ensures excellent electrical noise immunity. For the detonation velocity measurement a PE tube with an inner diameter of $14 \mathrm{~mm}$ was used, which was equipped with three optical fibers with a distance of $17 \mathrm{~mm}$ between them. The amount of compound $\mathbf{1}$ used for the test was $11.6 \mathrm{~g}$ resulting in a density of $0.699 \mathrm{~g} \mathrm{~cm}^{-3}$. The compound was loaded into the PE tube and manually compressed with a force of ca. $30 \mathrm{~N}$. As a booster charge $0.30 \mathrm{~g}$ of nitropenta (PETN) were added on top and carefully compressed manually using ca. $20 \mathrm{~N}$ force. Initiation was achieved with an electrically ignited detonator containing PETN and RDX (ORICA, DYNADET C2-25MS). To evaluate the used method, the same setup was employed for measuring the detonation velocity of RDX under the same conditions. $14.4 \mathrm{~g}$ of RDX were filled into the tube $\left(\rho=0.869 \mathrm{~g} \mathrm{~cm}^{-3}\right)$ and for best comparison of the measured values, also $0.30 \mathrm{~g}$ of PETN were added on top of the RDX. The results of the measurement can be seen in Table 10. The measured values between fiber 1 and 2 and between 2 and 3 were averaged and compared to the values computed with the EXPLO5 (version 5.04) software [37]. The recorded values for both measurements (RDX as well as compound 1) are in surprisingly good agreement with the computed values and differ by less than $200 \mathrm{~m} \mathrm{~s}^{-1}$ for compound 1 and only $41 \mathrm{~m} \mathrm{~s}^{-1}$ for RDX. 
Table 10. Calculated and measured detonation velocities of 1 and RDX

\begin{tabular}{|l|c|c|}
\hline & $\mathbf{1}$ & RDX \\
\hline mass $(\mathrm{g})$ & 11.6 & 14.4 \\
\hline density $\left(\mathrm{g} \mathrm{cm}^{-3}\right)$ & 0.699 & 0.869 \\
\hline $\mathrm{V}_{\text {det, exp. }\left(\mathrm{m} \mathrm{s}^{-1}\right)}$ & 4384 & 5339 \\
\hline $\mathrm{V}_{\text {det, theor. }}\left(\mathrm{m} \mathrm{s}^{-1}\right)$ & 4568 & 5370 \\
\hline
\end{tabular}

\section{Conclusion}

From this combined theoretical and experimental study the following conclusions can be drawn:

- Diaminouronium nitriminotetrazolate (1) and diaminouronium 1-methyl nitriminotetrazolate (2) were prepared in high yield and purity from the corresponding nitriminotetrazole and diaminourea.

- The crystal structures of $\mathbf{1}$ and $\mathbf{2}$ were determined by low-temperature singlecrystal X-ray diffraction. The compounds crystallize in the space groups $P n$ and $P 2_{1} 2_{1} 2_{1}$ with densities of 1.806 and $1.585 \mathrm{gcm}^{-3}$ respectively. Additionally both compounds were fully characterized by vibrational spectroscopy (IR and Raman) ${ }^{1} \mathrm{H}$ and ${ }^{13} \mathrm{C}$ NMR, mass spectroscopy, and elemental analysis.

- Thermal stabilities of $\mathbf{1}$ and $\mathbf{2}$ were investigated by DSC and decompose at 198 and $204{ }^{\circ} \mathrm{C}$ respectively.

- The sensitivities of towards friction, impact and electrostatic discharge were investigated by BAM methods. 1 and $\mathbf{2}$ were found to have impact sensitivities of $5 \mathrm{~J}$ and $3 \mathrm{~J}$ respectively, friction sensitivities of $108 \mathrm{~N}$ and $160 \mathrm{~N}$ respectively, and ESD sensitivities of $0.2 \mathrm{~J}$ and $0.15 \mathrm{~J}$ respectively. These are within the range of commonly-used high explosives such as RDX.

- Using calculated heats of formation and experimentally obtained crystal densities the detonation parameters (heat of explosion, explosion temperature, detonation pressure and velocity) were calculated. 1 has a detonation velocity of $8979 \mathrm{~m} \mathrm{~s}^{-1}$ and a detonation pressure of $337 \mathrm{kbar}$. 2 has a detonation velocity of $8172 \mathrm{~m} \mathrm{~s}^{-1}$ and a detonation pressure of $252 \mathrm{kbar}$.

\section{Experimental Part}

Caution! Methylated and unmethylated 5-nitriminotetrazole and their salts are energetic materials with increased sensitivities towards shock and friction. Therefore, proper safety precautions (safety glass, face shield, earthened equipment and shoes, Kevlar ${ }^{\circledR}$ gloves and ear plugs) have to applied while synthesizing and handling the described compounds. 
All chemicals and solvents were employed as received (Sigma-Aldrich, Fluka, Acros). ${ }^{1} \mathrm{H}$ and ${ }^{13} \mathrm{C}$ spectra were recorded using a JEOL Eclipse 270, JEOL EX 400 or a JEOL Eclipse 400 instrument. The chemical shifts quoted in ppm in the text refer to typical standards such as tetramethylsilane $\left({ }^{1} \mathrm{H},{ }^{13} \mathrm{C}\right)$. To determine the melting and decomposition temperatures of the described compounds a Linseis PT $10 \mathrm{DSC}$ (heating rate $5^{\circ} \mathrm{C} \mathrm{min}^{-1}$ ) was used. Infrared spectra were measured using a Perkin Elmer Spectrum One FT-IR spectrometer as $\mathrm{KBr}$ pellets. Raman spectra were recorded on a Bruker MultiRAM Raman Sample Compartment D418 equipped with a Nd-YAG-Laser (1064 nm) and a LN-Ge diode as detector. Mass spectra of the described compounds were measured at a JEOL MStation JMS 700 using FAB technique. To measure elemental analyses a Netsch STA 429 simultaneous thermal analyzer was employed.

\section{Diaminouronium 5-nitriminotetrazolate (1)}

5-Nitriminotetrazole $(0.89 \mathrm{~g}, 6.85 \mathrm{mmol})$ is dissolved in a few milliliters of water and added to a solution of diaminourea $(0.62 \mathrm{~g}, 6.85 \mathrm{mmol})$. The mixture was warmed, stirred at elevated temperature for ten minutes and the solvent was removed under vacuum. The white solid residue was recrystallized from ethanol to yield $1.96 \mathrm{~g}(6.10 \mathrm{mmol}, 89 \%)$ of 2 as a white crystalline material.

$\operatorname{DSC}\left(5{ }^{\circ} \mathrm{C} \min ^{-1},{ }^{\circ} \mathrm{C}\right): 180^{\circ} \mathrm{C}$ (m.p.), $198^{\circ} \mathrm{C}(\mathrm{dec}$ ) $)$ IR $\left(\mathrm{KBr}, \mathrm{cm}^{-1}\right): \tilde{v}=3550$ (s), 3414 (vs), 3234 (s), 2321 (w), 2024 (w), 1692 (s), 1637 (s), 1617 (vs), 1543 (m), 1512 (s), 1441 (m), 1385 (m), 1326 (s), 1229 (m), 1136 (s), 1110 (m), 1089 (m), 1062 (m), 1031 (m), 1006 (w), 963 (m), 921 (w), 870 (w), 773 (m), 746 (m), 696 (m), 623 (s), 570 (m), 482 (m); Raman (1064 nm, $\left.250 \mathrm{~mW}, 25^{\circ} \mathrm{C}, \mathrm{cm}^{-1}\right): \tilde{v}=1542$ (100), 1447 (4), 1390 (8), 1340 (2), 1327 (32), 1232 (4), 1150 (9), 1112 (3), 1081 (7), 1030 (42), 1017 (60), 962 (2), 921 (5), 875 (6), 748 (2), 741 (14), 578 (5), 486 (7), 430 (2), 420 (14), 384 (9), 252 (10); ${ }^{1} \mathrm{H}$ NMR (DMSO- $d_{6}, 25$ $\left.{ }^{\circ} \mathrm{C}, \mathrm{ppm}\right) \delta: 8.56\left(\mathrm{~s}, 8 \mathrm{H},-\mathrm{NH}-\mathrm{NH}_{2},-\mathrm{NH}_{3}{ }^{+}\right) ;{ }^{13} \mathrm{C}$ NMR (DMSO- $\left.d_{6}, 25{ }^{\circ} \mathrm{C}, \mathrm{ppm}\right) \delta: 159.3$ $\left(\mathrm{C}(\mathrm{O})\left(\mathrm{NHNH}_{2}\right)\left(\mathrm{NHNH}_{3}{ }^{+}\right)\right), 158.0\left(\mathrm{CN}_{4}\right) ; \mathrm{m} / \mathrm{z}\left(\mathrm{FAB}^{+}\right): 91.1\left[\mathrm{C}(\mathrm{O})\left(\mathrm{N}_{2} \mathrm{H}_{3}\right)_{2}+\mathrm{H}^{+}\right] ; \mathrm{m} / \mathrm{z}\left(\mathrm{FAB}^{-}\right)$: 129.0 [ $\mathrm{ATNO}_{2}{ }^{-}$]; EA $\left(\mathrm{C}_{2} \mathrm{H}_{8} \mathrm{~N}_{10} \mathrm{O}_{3}, 220.15\right)$ : calc.: C 10.91, H 3.66, N $63.62 \%$; found: $\mathrm{C} 11.19$, H 3.78, N $63.42 \%$; BAM drophammer: $5 \mathrm{~J}$; friction tester: $108 \mathrm{~N}$; ESD: $0.20 \mathrm{~J}$ (at grain size $500-1000 \mu \mathrm{m})$.

\section{Diaminouronium 1-methyl-5-nitriminotetrazolate (2)}

1-Methyl-5-nitriminotetrazole $(1.44 \mathrm{~g}, 10.0 \mathrm{mmol})$ is dissolved in a few milliliters of warm water and added to a solution of diaminourea $(0.90 \mathrm{~g}, 10.0 \mathrm{mmol})$. The mixture was heated to reflux for one minute and the solvent was removed under vacuum afterwards. The white solid residue was recrystallized from an ethanol/water mixture. Yield: $2.15 \mathrm{~g}(9.20 \mathrm{mmol}, 92 \%)$.

$\operatorname{DSC}\left(5{ }^{\circ} \mathrm{C} \min ^{-1},{ }^{\circ} \mathrm{C}\right): 163^{\circ} \mathrm{C}$ (m.p.), $204^{\circ} \mathrm{C}(\mathrm{dec}$ ) $)$ IR $\left(\mathrm{KBr}, \mathrm{cm}^{-1}\right): \tilde{v}=3415$ (s), 3371 (s), 3355 (s), 3326 (s), 3306 (s), 3230 (m), 3139 (m), 2956 (m), 2666 (m), 2019 (w), 1692 (s), 1619 (s), 1515 (s), 1466 (s), 1425 (m), 1411 (m), 1383 (s), 1324 (vs), 1295 (m), 1279 (m), 1240 (m), 1177 (m), 1163 (m), 1117 (m), 1108 (m), 1052 (w), 1032 (m), 989 (w), 960 (w), 928 (w), 881 (w), 774 (w), 752 (w), 740 (w), 691 (w), 636 (w), 581 (w); Raman (1064 nm, $\left.400 \mathrm{~mW}, 25^{\circ} \mathrm{C}, \mathrm{cm}^{-1}\right): \tilde{v}=3326$ (5), 3140 (3), 3008 (2), 2957 (13), 1690 (7), 1636 (2), 1504 (91), 1465 (27), 1411 (12), 1371 (5), 1322 (8), 1301 (36), 1240 (3), 1179 (9), 1109 (29), 1052 
(5), 1033 (100), 992 (5), 961 (10), 883 (11), 776 (2), 754 (9), 693 (17), 585 (7), 498 (9), 454 (4), 377 (8), 294 (20), 240 (7), 216 (5); ${ }^{1} \mathrm{H}$ NMR (DMSO- $\left.d_{6}, 25^{\circ} \mathrm{C}, \mathrm{ppm}\right) \delta: 7.79$ (s, 7H, -NH $\left.-\mathrm{NH}_{2}, \quad-\mathrm{NH}_{3}{ }^{+}\right), \quad 3.67\left(\mathrm{~s}, \quad 3 \mathrm{H}, \quad-\mathrm{CH}_{3}\right) ;{ }^{13} \mathrm{C}$ NMR (DMSO- $\left.d_{6}, \quad 25{ }^{\circ} \mathrm{C}, \quad \mathrm{ppm}\right) \delta: 159.6$ $\left(\mathrm{C}(\mathrm{O})\left(\mathrm{NHNH}_{2}\right)\left(\mathrm{NHNH}_{3}{ }^{+}\right)\right), 157.6\left(\mathrm{CN}_{4}\right), 33.1\left(\mathrm{CH}_{3}\right) ; \mathrm{m} / \mathrm{z}\left(\mathrm{FAB}^{+}\right): 91.1\left[\mathrm{C}(\mathrm{O})\left(\mathrm{N}_{2} \mathrm{H}_{3}\right)_{2}+\mathrm{H}^{+}\right]$; $\mathrm{m} / \mathrm{z}\left(\mathrm{FAB}^{-}\right)$: 143.0 [1-MeATNO${ }_{2}^{-}$]; EA $\left(\mathrm{C}_{3} \mathrm{H}_{10} \mathrm{~N}_{10} \mathrm{O}_{3}, 234.18\right)$ : calc.: $\mathrm{C} 15.39, \mathrm{H} 4.30, \mathrm{~N}$ $59.81 \%$; found: C 15.30, H 4.07, N 59.98 \%; BAM drophammer: $3 \mathrm{~J}$; friction tester: $160 \mathrm{~N}$; ESD: $0.15 \mathrm{~J}$ (at grain size $100-500 \mu \mathrm{m}$ ).

\section{Acknowledgment}

Financial support of this work by the Ludwig-Maximilian University of Munich (LMU), the U.S. Army Research Laboratory (ARL), the Armament Research, Development and Engineering Center (ARDEC), the Strategic Environmental Research and Development Program (SERDP) and the Office of Naval Research (ONR Global, title: "Synthesis and Characterization of New High Energy Dense Oxidizers (HEDO) - NICOP Effort ") under contract nos. W911NF-09-2-0018 (ARL), W911NF-09-1-0120 (ARDEC), W011NF-09-10056 (ARDEC) and 10 WPSEED01-002 / WP-1765 (SERDP) is gratefully acknowledged. The authors acknowledge collaborations with Dr. Mila Krupka (OZM Research, Czech Republic) in the development of new testing and evaluation methods for energetic materials and with Dr. Muhamed Sucesca (Brodarski Institute, Croatia) in the development of new computational codes to predict the detonation and propulsion parameters of novel explosives. We are indebted to and thank Drs. Betsy M. Rice and Brad Forch (ARL, Aberdeen, Proving Ground, MD) and Mr. Gary Chen (ARDEC, Picatinny Arsenal, NJ) for many helpful and inspired discussions and support of our work.

\section{References}

[1] L. V. De Yong, G. Campanella, J. Hazard. Mater. 1989, 21, 125.

[2] T. M. Klapötke, J. Stierstorfer, J. Am. Chem. Soc. 2009, 131(3), 1122.

[3] A. K. Sikder, N. Sikder, J. Hazard. Mater. 2004, A112, 1.

[4] P. Carlqvist, H. Ostmark, T. Brinck, J. Phys. Chem. A 2004, 108, 7463.

[5] M. H. V. Huynh, M. A. Hiskey, T. J. Meyer, M. Wetzler, Proc. Natl. Acad. Sci. USA 2006, 103, 5409-5412.

[6] N. Fischer, T. M. Klapötke, S. Scheutzow, J. Stierstorfer, Cent. Eur. J. Energetic Mater. 2008, 5, 3.

[7] T. M. Klapötke, J. Stierstorfer, A. U. Wallek, Chem. Mater. 2008, 20, 4519-4530.

[8] Z. Li, W. Zhu, J. Yu, X. Ma, Z. Lu, S. Xiao, Synth. Commun. 2006, 36, 2613-2619.

[9] T. M. Klapötke, J. Stierstorfer, Helv. Chim. Acta 2007, 90, 2132-2150.

[10] CrysAlis RED, Oxford Diffraction Ltd., Version 1.171.27p5 beta (release 01-04-2005 CrysAlis171 .NET). 
[11] A. Altomare, G. Cascarano, C. Giacovazzo, A. Guagliardi, Appl. Cryst. 1993, 26, 343.

[12] G. M. Sheldrick, Shelxl-97, Program for the Refinement of Crystal Structures, University of Göttingen, Germany, 1994.

[13] L. Farrugia, J. Appl. Cryst. 1999, 32, 837-838.

[14] A. L. Spek, Platon, A Multipurpose Crystallographic Tool, Utrecht University, Utrecht, The Netherlands, 1999.

[15] Crystallographic data for the structure(s) have been deposited with the Cambridge Crystallographic Data Centre. Copies of the data can be obtained free of charge on application to The Director, CCDC, 12 Union Road, Cambridge CB2 1EZ, UK (Fax: int.code_(1223)336-033; e-mail for inquiry: fileserv@ccdc.cam.ac.uk; e-mail for deposition: deposit-@ccdc.cam.ac.uk).

[16] J. Stierstorfer, Dissertation, Energetic Materials based on 5-Aminotetrazole, LudwigMaximilians-Universität München, 2009.

[17] T. M. Klapötke, J. Stierstorfer, B. Weber, Inorg. Chim. Acta 2009, 362(7), 2311-2320.

[18] R. Wang, Y. Guo, Z. Zeng, B. Twamley, J. M. Shreeve, Chem. - Eur. J. 2009, 15, 2625.

[19] J. Bernstein, R. E. Davis, L. Shimoni, N.-L. Chang, Angew. Chem. Int Ed. 1995, 34, 1555-1573.

[20] G. Geisberger, T. M. Klapötke, J. Stierstorfer, Eur. J. Inorg. Chem. 2007, 30, 4743 4750 .

[21] M. Tremblay, Can. J. Chem. 1965, 43, 1154-1157.

[22] J. Svetlik, A. Martvon, J. Lesko, Chem. Papers 1979, 33, 521.

[23] M. Hesse, H. Meier, B. Zeeh, Spektroskopische Methoden in der organischen Chemie, 7th ed., Thieme, Stuttgart, New York, 2005.

[24] NATO standardization agreement (STANAG) on explosives, impact sensitivity tests, no. 4489, 1st ed., Sept. 17, 1999.

[25] WIWEB-Standardarbeitsanweisung 4-5.1.02, Ermittlung der Explosionsgefährlichkeit, hier der Schlagempfindlichkeit mit dem Fallhammer, Nov. 8, 2002.

[26] http://www.bam.de

[27] NATO standardization agreement (STANAG) on explosive, friction sensitivity tests, no. 4487, 1st ed., Aug. 22, 2002.

[28] WIWEB-Standardarbeitsanweisung 4-5.1.03, Ermittlung der Explosionsgefährlichkeit oder der Reibeempfindlichkeit mit dem Reibeapparat, Nov. 8, 2002.

[29] Impact: Insensitive $>40 \mathrm{~J}$, less sensitive $\geq 35 \mathrm{~J}$, sensitive $\geq 4 \mathrm{~J}$, very sensitive $\leq 3 \mathrm{~J}$; friction: Insensitive $>360 \mathrm{~N}$, less sensitive $=360 \mathrm{~N}$, sensitive $<360 \mathrm{~N}$ a. $>80 \mathrm{~N}$, very 
sensitive $\leq 80 \mathrm{~N}$, extreme sensitive $\leq 10 \mathrm{~N}$; According to the UN Recommendations on the Transport of Dangerous Goods (+) indicates: not safe for transport.

[30] http://www.ozm.cz

[31] http://www.linseis.com

[32] M. J. Frisch et al., Gaussian 03, Revision B04, Gaussian Inc., Wallingford, CT, 2004.

[33] (a) J. W. Ochterski, G. A. Petersson, and J. A. Montgomery Jr., J. Chem. Phys. 1996, 104, 2598; (b) J. A. Montgomery Jr., M. J. Frisch, J. W. Ochterski, G. A. Petersson, J. Chem. Phys. 2000, 112, 6532.

[34] (a) L. A. Curtiss, K. Raghavachari, P. C. Redfern, J. A. Pople, J. Chem. Phys. 1997, 106(3), 1063; (b) E. F. C. Byrd, B. M. Rice, J. Phys. Chem. A 2006, 110(3), 10051013; (c) B. M. Rice, S. V. Pai, J. Hare, Comb. Flame 1999, 118(3), 445-458.

[35] P. J. Linstrom, W. G. Mallard, Eds., NIST Chemistry WebBook, NIST Standard Reference Database Number 69, June 2005, National Institute of Standards and Technology, Gaithersburg MD, 20899 (http://webbook.nist.gov).

[36] (a) H. D. B. Jenkins, H. K. Roobottom, J. Passmore, L. Glasser, Inorg. Chem. 1999, 38(16), 3609-3620. (b) H. D. B. Jenkins, D. Tudela, L. Glasser, Inorg. Chem. 2002, 41(9), 2364-2367.

[37] M. Sućeska, EXPLO5.04 program, Zagreb, Croatia, 2010.

[38] (a) M. Sućeska, Materials Science Forum, 2004, 465-466, 325-330. (b) M. Sućeska, Propellants, Explos., Pyrotech. 1991, 16, 197-202. (c) M. Sućeska, Propellants, Explos., Pyrotech. 1999, 24, 280-285. (d) M. L. Hobbs, M. R. Baer, Proc. of the 10th Symp. (International) on Detonation, ONR 33395-12, Boston, MA, July 12-16, 1993, p. 409. 